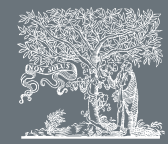

ELSEVIER

\title{
Biosafety capacity building: experiences and challenges from a distance learning approach ${ }^{\star}$
}

\section{Ine Pertry ${ }^{1,2}$, Silvia Sabbadini ${ }^{3}$, Sofie Goormachtig ${ }^{4,5}$, Yvonne Lokko ${ }^{6}$, Godelieve Gheysen ${ }^{1,7}$, Sylvia Burssens ${ }^{1,2, a}$ and Bruno Mezzetti ${ }^{3, a}$}

\footnotetext{
${ }^{1}$ VIB, Institute of Plant Biotechnology Outreach, Technologiepark 3, B-9052 Gent, Belgium

${ }^{2}$ Ghent University, Institute of Plant Biotechnology Outreach, Department Plant Biotechnology and Bio-informatics, Technologiepark 3, B-9052 Gent, Belgium

${ }^{3}$ Department of Agricultural, Food and Environmental Sciences, Università Politecnica delle Marche, Via Brecce Bianche, 60100 Ancona, Italy

${ }^{4}$ VIB, Department of Plant Systems Biology, Technologiepark 927, B-9052 Gent, Belgium

${ }^{5}$ Ghent University, Department Plant Biotechnology and Bio-informatics, Technologiepark 927, B-9052 Gent, Belgium

${ }^{6}$ Agri-business Development Unit United Nations Industrial Development Organization (UNIDO), Wagramerstrasse 5, P.O. Box 300, A-1400 Vienna, Austria

${ }^{7}$ Department of Molecular Biotechnology, Ghent University, Coupure links 653, B-9000 Ghent, Belgium
}

Biotechnology is revolutionizing industrial and agricultural practice as the number of commercial biotechnology products is increasing each year. Simultaneously, several regulatory approaches are put into place to allow technological advancement while preserving public health and the environment. Developing and/or emerging countries often face major barriers to access biotechnologies and biotechnology derived products as they frequently lack the institutional capacities and professional competence in exercising regulatory oversight. To address this need, intensive biosafety capacity building is required. Different training approaches can be used to train individuals in biosafety ranging from long-term leading to a postgraduate certificate or a Masters degree, to short term courses. In this paper, we discuss the applicability of a different approach to biosafety capacity building based on a distance e-learning system, the UNIDO e-Biosafety program that has been annually organized at the Marche Polytechnic University (MPU) in Italy and Ghent University (UGent) in Belgium since 2006. Even though there are some challenges, we can conclude based on our experience that distance learning in combination with on-campus tuition is amendable for biosafety capacity building.

\section{Introduction}

Since the first commercial release of GM crops in the mid 90s, GM technology has been widely adopted. In 2012, 28 countries all over the world planted 170.3 million hectares of GM crops and biotechnology is still revolutionizing industrial and agricultural practice as the number of commercial products is exponentially increasing and many new applications are in the pipeline each

\footnotetext{
This is an open-access article distributed under the terms of the Creative Commons Attribution-NonCommercial-No Derivative Works License, which permits non-commercial use, distribution, and reproduction in any medium, provided the original author and source are credited.

Corresponding author: Pertry, I. (ine.pertry@ugent.be, ine.pertry@gmail.com)

${ }^{\text {a }}$ Sylvia Burssens and Bruno Mezzetti contributed equally to this work.
}

year [1-3]. Adequate safety standards are required to allow technological advancement while preserving public health and the environment. This is reflected by the worldwide ratification by over 80 countries of the Cartagena Protocol on Biosafety (CPB), which regulates the transboundary movement, transit, handling and use of living modified organisms. Implementation of the CPB requires the presence of institutional capacities and professional competence in exercising regulatory oversight [4,5]. In 2012, 20 developing countries grew 52\% of the GM crops worldwide indicating that for some developing countries the adoption rate of GM crops is significantly higher as compared to their industrialized counterparts. While several African countries run research programs focusing on GM crops, in 2012 only 7 (Burkina Faso, 
Cameroon, Egypt, Kenya, Nigeria, South-Africa, and Uganda) conducted confined field trials and only 4 countries on the African continent (Burkina Faso, Egypt, South Africa and Sudan) cultivate GM crops [2,6-9].

GM technology and GM products are also applicable in other sectors such as in health care delivery. In 1982, the first recombinant DNA product, the human insulin drug (Humulin) was released $[10,11]$. Since then several other drugs have been produced using GM products [12]. Many commercially available bioengineered industrial enzymes derived from GM microbes, are used in the food industry [13]. With improved GM technology, the potential use of novel enzymes for the sustainable growth of other sectors such as energy, is growing [14,15].

Most developing countries however, lack the capacity to develop, handle and/or commercialize these biotechnology products and often face major barriers to access the technology and derived products. Many developing and emerging countries are currently setting up and/or implementing National Biosafety Frameworks in compliance with the $\mathrm{CPB}$ to overcome this major hurdle. As a result, there is a rising demand for professionals who can effectively deal with biological risk assessment and management. Article 22 of the Cartagena protocol particularly deals with capacity-building. It states that 'the Parties shall cooperate in the development and/or strengthening of human resources and institutional capacities in biosafety, including biotechnology to the extent that it is required for biosafety, for the purpose of the effective implementation of this Protocol in developing country Parties, ...' [4]. In reality, similar needs are also of interest for the EU, EECCA countries and other developed countries facing the challenge to manage the introduction and application of biotechnology in agriculture and other industries. The need to strengthen professional expertise in biosafety regulations has thus become a priority for many national and international developmental programs.

\section{Biosafety capacity development}

Biosafety capacity building is a complex task and requires a multidisciplinary approach, the main components being human resource development, institutional and policy development for regulatory bodies and relevant research institutions, to enable them efficiently and effectively use biotechnology products particularly GM crops, microbes and/or their processed products. In the last decade, various developmental agencies and donors, notably the Food and Agricultural Organization of the United Nations (FAO), the Global Environment Facility (GEF) and the United Nations Environment Programme (UNEP), have been supporting the biosafety capacity building needs of developing/emerging countries through their technical assistance programs $[16,17]$. The range of activities include: (i) the development of national policies and formulation of regulations; (ii) GMO detection and monitoring including equipping of laboratories and harmonizing protocols among countries; (iii) facilitating effective communication and public awareness and (iv) human resource development in biosafety.

For human resource development, different training concepts can be applied to train individuals in biosafety [18]. In-depth specialization can be delivered by opting for formal education from a university at a postgraduate or Master level. This allows an intensive and hands-on practical training resulting in a profound development of the required competencies. Despite the advantage of this option with the resulting academic accreditation, long term university training has limited appeal to professionals as it requires them to take time off for full time study. In addition, it can be very expensive for students as well as for course providers. As such, only few long-term Master's degree courses in Biosafety are being organized worldwide. Short term courses on the other hand can rapidly and specifically target the needed skills of different stakeholders and are less time consuming for professionals. Moreover, the costs arising from their organization are much lower compared to the long-term training at a Masters or postgraduate diploma level. As a result of this, short term courses and workshops are the most frequent mode of biosafety capacity building (Biosafety Clearing House, http://bch.cbd.int/database/activities/) [7,19] and several such training courses have been organized by different international organizations and institutions, including the International Centre for Genetic Engineering (ICGEB), FAO, UNEP-GEF and Michigan State University $[9,19,20]$.

\section{The UNIDO e-biosafety program}

Short term biosafety courses are very suitable to provide information and training for specific skills and needs [9]. Although short term courses have contributed significantly to the immediate implementation of the Cartagena protocol, our experience shows that they cannot deliver the intensive training that is required to deal effectively with the complexity of issues related to biological risk assessment and management. In view of this, a new approach was considered as a distance learning program conducted on-line, which combines the advantages of short- and long-term courses. This e-course is a one year academically accredited program characterized by the highest educational standards. The concept was born from UNIDO's aim to promote South-South cooperation in biosafety training, information exchange and advisory services. It was initiated in a pilot project that ran between 2003 and 2005 at the University of Concepcion, Chile providing the conceptual modus operandi for the first comprehensive and academically accredited training program in biosafety [18]. In 2006 regional nodes were established in Malaysia - University of Malaya; Belgium - Ghent University, Ghent; and Italy - Marche Polytechnic University, Ancona. In 2007, the second Latin America node was started in Belo Horizonte (Brazil) with the Pontificia Universidade Catolica de Minas Gerais. Currently, the course is organized annually at the Marche Polytechnic University (MPU) and Ghent University (UGent) as part of UNIDO's international e-Biosafety Network (http://binas.unido.org/moodle/).

The UNIDO e-Biosafety program aims at ensuring long-term sustainability through training of indigenous key resource persons ('train the trainers' approach) and strengthening the institutional capacities of regulatory agencies that must meet the requirements of national legislation and international agreements (Cartagena Protocol, WTO agreements, Codex Alimentarius, etc.). The structure of the program ensures that trainees from different backgrounds such as life sciences or law successfully acquire the entire range of disciplines and skills needed as biosafety practitioners. Towards this end the training material includes introductory sections teaching fundamental aspects of (plant) biotechnology and its current applications which complement 
the main core introducing the basics of risk assessment and regulatory structures. In separate sections students gain in-depth knowledge in food \& feed as well as environmental safety assessment. Students are provided with an overview on national and international regulatory systems and trained in risk perception and communication. It delivers a solid basis to set up, implement and manage regulatory biosafety frameworks related to plant biotechnology. Furthermore, it allows participants to acquire the requisite skills to formulate applications for the release of genetically modified organisms (GMO) into the environment and to manage public policy issues with an integration of science, government policies, industry and civil society. Even though the course mainly targets individuals involved in biosafety in government or private agencies, it is also open to participants with a general interest in the political, legal and ethical aspects of biotechnology.

The e-Biosafety training program is accessible through a dedicated online Virtual Learning Environment (VLE; https://moodle.org/about/). The VLE is intended both for students and faculty and contains all training materials and resources (library, videos, etc.). The training material is divided into seven separate modules which are released iteratively as theoretical lessons. For each module, students engage in online discussion on topics given by the course faculty and complete a written assignment. At the end of the course students are expected to prepare for their dissertation (final assignment) a biosafety dossier on a GM plant of their choice, under the supervision of an individually assigned tutor. Dissertation, assignments, participation in online discussion as well as a final examination count towards the final grade in accordance with prevailing academic regulations of the host university. Upon successful completion of the program, students are awarded with an academically accredited postgraduate certificate at UGent or a First Level Masters diploma at MPU.

The pilot phase of this program clearly identified the need for dedicated hands-on tuition in addition to the online tutorials to allow students to intensify their knowledge on core risk assessment topics. As a result, one to two weeks on-campus sessions have been organized at UGent and MPU, both open to all students from the different network nodes. These sessions featured lectures and seminars by high-level experts from different fields (such as the AgroIndustry sector, the plant breeding and biotechnology community, intellectual property and biosafety issues and science communication) as well as the detailed discussion of case studies, PC and laboratory exercises. The main aim was to provide students and participants with the unique opportunity to develop advanced skills in formulating and assessing applications for environmental releases and/or food \& feed use of biotechnology-derived products through practical training provided by renowned and experienced competent institutions and their local faculty (MPU, UGent) and to strengthen professional expertise in biosafety by interacting with recognized international experts with decades long experience in modern biotechnology and risk assessment.

For the past 3 years, European Food Safety Authority (EFSA) representatives have been invited to the MPU on campus session to introduce the European experience in the regulation of GMOs for Food/Feed/Environmental release and the main aspects of the scientific basis related to food and environmental risk assessment on products derived by biotechnology applications. In addition, real life scenarios and cases were presented which enriched the discussion during these on-campus sessions.

The on-campus sessions at UGent also allowed to include two practical training sessions intended to familiarise trainees with little or no experience in plant biotechnology. During the first exercise, focusing on the techniques associated with plant transformation, students use Agrobacterium tumefaciens to introduce DNA into Arabidopsis thaliana root tissue and subsequently determine the degree of transformation efficiency by analyzing the expression of the reporter gene $\beta$-glucuronidase (gus). The second exercise familiarises students with GMO detection methods to detect, identify and quantify GMOs in food and feed products.

The modular set up of the course in combination with the oncampus sessions allows flexibility and tailoring of the content to regional and/or specific needs. As such, we are able to include specific training material as has been done in the past for example with a specific focus on crop species and aspects of priority for different cultivation areas (in particular the Balkans, Mediterranean and Central Africa areas).

From October 2006 to October 2012, 100 students from 37 different countries participated in the course at the UGent and MPU network nodes (see Table 1). More than half of the students came from Africa (58\%), followed by Europeans (23\%). Only a minority came from Asia, Russia and Middle-East (10\%), Central and South America (7\%) or North-America (2\%). East African countries have been well represented and more than one fifth of the participants were Kenyans. Generally the gender balance was not optimal as only $37 \%$ of the trainees were female. The

TABLE 1

UGent and MPU participant nationalities for the e-Biosafety program 2006-2012

\begin{tabular}{lllll}
\hline Africa (58) & Europe (23) & $\begin{array}{l}\text { Asia, Russia and } \\
\text { Middle East (10) }\end{array}$ & $\begin{array}{l}\text { North } \\
\text { America (2) }\end{array}$ & $\begin{array}{l}\text { Central and } \\
\text { South America (7) }\end{array}$ \\
\hline Kenya (21) & Congo (2) & Italy (11) & India (3) & US (1) \\
\hline Ghana (5) & Tanzania (2) & Belgium (4) & China (3) & Canada (1) \\
\hline Uganda (5) & Rwanda (2) & Croatia (3) & Vietnam (1) & Argentina (1) \\
\hline Cameroon (4) & Sudan (1) & Ireland (1) & Russia (1) & Paraguay (1) \\
\hline Ethiopia (4) & Malawi (1) & Romania (1) & Malaysia (1) & Colombia (1) \\
\hline Libya (3) & Mauritius (1) & UK (1) & Pakistan (1) & \\
\hline Nigeria (3) & Zimbabwe (1) & The Netherlands (1) & & \\
\hline Burkina Faso (2) & Swaziland (1) & Germany (1) & & \\
\hline
\end{tabular}


TABLE 2

Results in percentage of a questionnaire completed by 45 MPU and UGent alumni (2006-2012) evaluating UNIDO's e-Biosafety program (July 2013)

\begin{tabular}{|c|c|c|c|c|c|c|c|}
\hline & $\mathbf{E}$ & VG & G & $\mathbf{M}$ & $\mathbf{S}$ & $\mathbf{I}$ & \\
\hline \multicolumn{8}{|l|}{ General } \\
\hline How would you rate the organization of the course? & 31.11 & 53.33 & 15.56 & 0 & 0 & 0 & \\
\hline Did the course meet your expectations? & 28.89 & 53.33 & 17.78 & 0 & 0 & 0 & \\
\hline How did you appreciate the distance learning method? & 22.22 & 56.82 & 13.33 & 6.67 & 2.22 & 0 & \\
\hline $\begin{array}{l}\text { Has the acquired knowledge been valuable for your work } \\
\text { at your home institution/country? }\end{array}$ & 44.44 & 31.11 & 15.56 & 4.44 & 2.22 & 0 & $2.22 \mathrm{NY}$ \\
\hline Has the obtained degree opened up career opportunities? & 20.00 & 22.22 & 22.22 & 11.11 & 2.22 & 6.67 & $15.56 \mathrm{NY}$ \\
\hline \multicolumn{8}{|l|}{ Course content } \\
\hline Theoretical lectures & 31.11 & 48.89 & 15.56 & 2.22 & 2.22 & 0 & \\
\hline Practical exercises & 4.44 & 37.78 & 31.11 & 17.78 & 0 & 6.67 & $2.22 \mathrm{NO}$ \\
\hline Course material & 35.56 & 40.00 & 15.56 & 4.44 & 0 & 0 & $4.44 \mathrm{NO}$ \\
\hline
\end{tabular}

E: excellent; VG: very good; G: good; M: moderate; S: sufficient; I: insufficient.

NY: not yet; NO: no opinion.

success rate was approximately $79 \%$ and most of the trainees are currently engaged with national regulatory authorities.

In 2013, a questionnaire was sent out to 79 course alumni to evaluate the e-biosafety program. The form was returned by 45 alumni who reviewed the following issues:

- General organization of the course and the e-distance learning method

- Did the course meet the expectations?

- Course content and material

- Value for current work and career opportunities

Participants were able to select from the following answers: excellent, very good, good, moderate, sufficient and insufficient and had the opportunity to add comments to the specific topics if desired. For some topics participants expressed no opinion or indicated that there was not yet a result, which was included as such in the results (see Table 2). Overall, the outcome shows that the alumni are very satisfied with the course and that it has met their expectations. The overall majority rated the course organization, content and material ranging from good to excellent. With regards to the practical exercises, mixed opinions were received: one person had no opinion on the topic and others valued them only moderate or even insufficient. And even though the majority indicated they were satisfied, participants would prefer even more practical training. This result can be explained in two ways. First, the questionnaire was sent out to all alumni. As the hands-on lab training at the UGent on campus session only started in 2009, not all alumni had the opportunity to take part in this. Second, even though the UGent on campus session is open to the students registered at MPU, very few have participated in the past years, most likely because of limited time and/or resources. Nevertheless, as this evaluation shows a request to have this hands-on lab training in addition to the discussion of case studies, it should be considered to organize these exercises at the MPU on campus session as well. Even though the majority highly appreciated the edistance learning method mainly because it allows to continue official duties while studying, some indicated it can be a challenge, especially in developing countries where a suitable internet connection can be a limiting factor.

Looking at the impact of the e-biosafety program, the overall majority indicated that the course has been very valuable to their current work in their institution as they are often involved in field trials, biosafety committees and regulatory agencies. With regards to career opportunities, different opinions can be observed. While some indicated that the accreditation opened up or strengthened career opportunities by allowing them to be involved in biosafety trainings or committees others mentioned it did not yet do so. One aspect that was mentioned as limiting by the alumni was the difference in the obtained degree between Ghent and Ancona. Indeed, due to country-bound rules, Ghent University issues an accredited postgraduate certificate, while MPU offers a First Level Master diploma. This postgraduate certificate was scored as less beneficial compared to the First Level Master diploma. Unfortunately, we are afraid that this discrepancy will not be solved in the near future. Some students also indicated it would be valuable to have the possibility to complete the training program with a second year master program. Although this could be a future perspective, it would be challenging to organize as the most value for such an additional year would come from hands on training in lab work and dossier preparation which cannot be organized through e-distance learning.

Finally, several of the returned questionnaires requested to set up a solid alumni network to bring alumni in contact with each other, provide them with a forum and updated material and link them to ongoing courses. Following this observation, we will look into the options on how to organize this in the future.

\section{Conclusion}

Building capacities for biosafety in developing countries is crucial to enable them explore the range of biotechnologies and their derived products to sustainably boost production in agriculture and other bio-industries. Our experience in the human resource development aspect shows that long term distance e-learning brings several advantages to biosafety capacity building such as minimizing geographical constraints and costs. It is an attractive approach for professionals as it allows them flexibility to combine the training with their daily profession. In this way it can deliver in depth training according to the 'train the trainers' principle, resulting in a multiplication effect of capacity building. Despite these advantages of the distance e-learning system, however, some challenges still remain. The e-learning system highly benefitted 
from the additional hands-on training during the on-campus sessions. This of course implies that participants require the means and the time to travel to the network nodes where the training is being organized. In addition, a constant maintenance of the developed curriculum is required to ensure the continuous application of quality standards. Besides these educational challenges, the course set up also encountered several logistical challenges, which may account for a lower rate of success. First of all students need to have access to a suitable internet connection. Secondly, although the distance e-learning can minimize geographical constraints, it cannot lift existing language barriers. To date, the UNIDO course run by the MPU and UGent nodes is solely delivered in English. We do however experience a need to deliver the course in other languages particularly French and Spanish, especially for the French speaking community in Africa. Finally, the biggest challenge of this project appears to be the sustainability. Despite the fact that biosafety is a major issue for society and decision making on the implementation of the technology, and remains an important priority for countries to meet their national commitments under the Convention of Biodiversity (CBD) and the $\mathrm{CPB}$ [21], funding for biosafety capacity development keeps decreasing every year. As a result the number of scholarships dropped significantly although they are essential to give students from developing countries the opportunity to take part in this course. Moreover, it also resulted in a decreased number of network nodes where the course is being organized. At the start of this program in 2006, 5 nodes were member of UNIDO's international e-Biosafety Network. Due to lacking resources however, the
Universidad de Concepcion (Chili), the University of Malaya (Malaysia) and the Pontifical Catholic University of Sao Paulo (Brazil) no longer run this program at their universities.

It is generally recognized that proper institutional capacities need to be in place for countries to deal with the complex issues related to the adoption of GM-technology. It is therefore important to continuously bring to the attention of governments, developmental agencies and international organizations, the value of biosafety capacity development including training through formal degrees to encourage them to mobilize resources for these projects.

Overall, we can conclude that the distance e-learning system in combination with on-campus tuition is amendable for biosafety capacity building.

\section{Acknowledgements}

This paper was written within the framework of the FlandersUNIDO Risk Assessment Research Network (FURARN), funded by Research Foundation - Flanders.

The course concept was developed by George Tzotzos as early as 2002. Between 2002 and 2011, the web interface was developed and managed by George Tzotzos, Vladimir Samoilov and Magnus Bosse.

The authors would like to acknowledge UNIDO, ICS-UNIDO, Flemish Government - dept. Economy, Science and Innovation, Ministero dell'Ambiente e della Tutela del Territorio e del Mare and NEPAD for their financial support for the organization of the course and/or having provided student scholarships.

\section{References}

[1] Qaim M. The economics of genetically modified crops. Annu Rev Resour Econ 2009; 1:665-93.

[2] James C. Global Status of Commercialized Biotech/GM Crops: 2012. International Service for the acquisition of Agri-biotech Applications (ISAAA) Brief 44 2012. Ithaca, NY: ISAAA; 2013.

[3] RodrÍguez-Cerezo E. GM crops in the global pipeline, asynchronous approvals and challenges. In: ESOF 2010 Conference; 2010. http://ec.europa.eu/dgs/jrc/ downloads/jrc esof 2010 presentation_rodriguez cerezo.pdf.

[4] Secretariat of the Convention on Biological Diversity. Cartagena Protocol on Biosafety to the Convention on Biological Diversity. Montreal, Canada: Secretariat of the Convention on Biological Diversity; 2000, ISBN: 92-807-1924-6.

[5] Secretariat of the Convention on Biological Diversity. Cartagena Protocol on Biosafety Ratification List; 2013. http://www.cbd.int/doc/lists/cpb-ratifications. pdf.

[6] Eicher CK, Maredia K, Sithole-Niang I. Crop biotechnology and the African farmer. Food Policy 2006;31:504-27.

[7] Johnston S, Monagle C, Green J, Mackenzie R. Internationally funded training in biotechnology and biosafety: is it bridging the biotech divide?. United Nations University, Institute of Advanced Studies (UNU-IAS); 2008 , http://www.ias. unu.edu/sub page. aspx?catID $=111 \& d d I I D=673$.

[8] Sengooba T, Grumet R, Hancock J, Zawedde B, Kitandu L, Weebadde C, et al Biosafety education relevant to genetically engineered crops for academic and non-academic stakeholders in East Africa. Electron J Biotechnol 2009;12(1):1.

[9] Savadogo M. Confined field trials in Africa: a key step to safely perform experiments with genetically modified crops. African Union/NEPAD-African Biosafety Network of Expertise (NEPAD-ABNE), Environmental Biosafety ABNE Policy Brief No. 2; 2010. Available from http://www.nepadbiosafety.net/abne/wpcontent/uploads/2010/10/Env.-Biosafety-Policy-Brief-NO-2.pdf.

[10] FDA. Celebrating a Milestone: FDA's Approval of First Genetically-Engineered Product by FDA Historian Suzanne White. Selections From FDLI Update Series on FDA History; 2007. http://www.fda.gov/AboutFDA/WhatWeDo/History/

ProductRegulation/SelectionsFromFDLIUpdateSeriesonFDAHistory/ ucm081964.htm.

[11] Johnson IS. Human insulin from recombinant DNA technology. Science 1983;219:632-7. doi: 10.1126/science.6337396.

[12] Phillips T. Genetically modified organisms (GMOs): transgenic crops and recombinant DNA technology. Nature Educ 2008;1(1). Available from http:// www.nature.com/scitable/topicpage/genetically-modified-organisms-gmostransgenic-crops-and-732.

[13] Olempska-Beer ZS, Merker RI, Ditto MD, DiNovi MJ. Food-processing enzymes from recombinant microorganisms - a review. Regulatory Toxicol Pharmacol 2006; 45(July (2)):144-58.

[14] Rogers PL, Jeon YJ, Svenson CJ. Application of biotechnology to industrial sustainability. Process Safety Environ Protection 2005;83(November (6)):499-503.

[15] Davidson S. Sustainable bioenergy: genomics and biofuels development. Nature Educ 2008;1(1). Available from http://www.nature.com/scitable/topicpage/ sustainable-bioenergy-genomics-and-biofuels-development-44571.

[16] UNEP. A comparative analysis of experiences and lessons from the UNEP-GEF biosafety projects; $2006.48 \mathrm{p}$.

[17] FAO. Building biosafety capacities. FAO's experience and outlook; 2009. 53 pg.

[18] Hull R, Bosse M, Tzotzos G. Training for implementing risk assessment regulations for the release of GM crops. In: Aspects of Applied Biology 96, Agriculture: Africa's engine for growth - Plant science \& biotechnology hold the key; 2010 pp. $1-8$.

[19] UNEP. Education and training in biosafety: strategies for promoting the development and/or expansion of academic programmes in biosafety particularly at the degree and diploma level. UNEP/CBD/BS/CM-ET/2/2; 2007.

[20] Hall A. Capacity development for Agricultural biotechnology in developing countries: an innovation systems view of what it is and how to develop it. J Int Dev 2005;17:611-30.

[21] GEF. GEF 5 Focal area strategies. Biodversity strategy for GEF 5; 2010. Available from http://www.thegef.org/gef/GEF5_Biodiversity_Strategy. 